\title{
A greve de 1903: primórdios do movimento operário no Rio de Janeiro
}

\author{
The 1903 strike: origins of the workers' movement \\ in Rio de Janeiro
}

\author{
Carlos Augusto Addor \\ Professor Adjunto do Departamento de História \\ da Universidade Federal Fluminense \\ Rua São Salvador 50/303, Flamengo \\ 22231-130 Rio de Janeiro - RJ - Brasil \\ caaddor@uol.com.bril
}

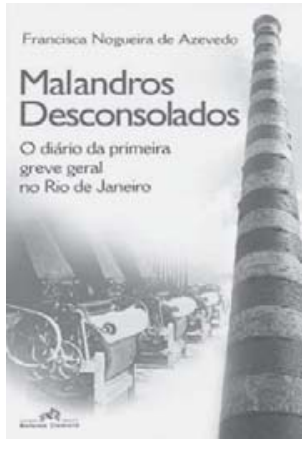

Azevedo, Francisca Nogueira de Malandros desconsolados: o diário da primeira greve geral no Rio de Janeiro. Rio de Janeiro: Relume Dumará, 2005. 227p.
A partir de uma pesquisa realizada basicamente com periódicos publicados na cidade do Rio de Janeiro na primeira década do século XX, a professora Francisca de Azevedo elaborou um original estudo sobre a greve de agosto/setembro de 1903 deflagrada na então capital federal da República brasileira. A originalidade do trabalho deve-se não apenas ao ineditismo de muitas das fontes primárias consultadas, mas principalmente à opção estilística da autora, segundo a qual "a narrativa histórica foi organizada em formato de crônica, sugerindo um diário" (p.29).

Com efeito, toda a estrutura do capítulo 3 do livro, "O diário da greve", que é o núcleo da obra, compreendendo 178 de suas 206 páginas (textos e ilustrações), é ordenada com base em uma seqüência cronológica, que abrange o período de 12 de agosto a 5 de setembro de 1903. A autora reproduz e comenta artigos, notícias e editoriais da imprensa carioca - em especial O Correio da Manhã e O Paiz, mas também O Malho e Rio Nu - acompanhando o dia-a-dia do movimento paredista e analisando suas origens e motivações, principais reivindicações, consolidação, expansão, declínio e encerramento, ao longo de quase um mês desse inverno carioca do início do século passado.

Os dois primeiros capítulos são introdutórios. No capítulo 1, a autora, com base principalmente em fontes secundárias, tece considerações gerais sobre "O Rio de Janeiro na virada do século XX": aceleração da urbanização, crescimento demográfico, a capital federal atraindo tanto migrantes internos como imigrantes europeus, expansão, ainda incipiente mas já em processo e dinâmica irreversíveis, da produção industrial. E, conseqüentemente, a formação de uma classe operária, constituída por um proletariado fabril mas também por inúmeras categorias profissionais vinculadas a outras atividades urbanas: o porto, os bancos, os transportes e o comércio em seus vários ramos, bares, hotéis, restaurantes.

No capítulo 2, "Os jornais e a greve", a autora explicita e justifica sua opção de estilo e de método: construir o livro em formato de crônica, sugerindo um diário da greve de 1903. Essa opção traz como principal vantagem recriar, a partir fundamentalmente da linguagem da época, o clima, o ambiente, a atmosfera do Rio de Janeiro afrancesado da Belle Époque; e o texto torna-se agradável ao leitor. Contribui também para 
essa recriação de um ambiente de época a publicação de ilustrações, charges e caricaturas, selecionadas de periódicos. Contudo, a opção traz também um problema: muitas vezes o leitor não percebe com clareza onde termina o artigo, o editorial (ou fragmento) de 1903 e onde começa a análise, o comentário, em suma, o texto da autora.

Ainda no capítulo 2 há um pequeno deslize, que não compromete absolutamente a qualidade da obra, mas deve ser reparado em uma eventual segunda edição. À página 27, afirma a autora, no primeiro parágrafo: "A greve desencadeada pelos trabalhadores têxteis em agosto de 1903 na cidade do Rio de Janeiro contribuiu, sem dúvida, para engrossar os movimentos que fizeram da primeira década republicana o período mais turbulento da cidade". Com certeza, a primeira década republicana (1889-1899) foi - com a Revolta da Armada, a Revolução Federalista no Sul e a Guerra de Canudos, para lembrar os movimentos sociais e/ou políticos mais marcantes - extremamente turbulenta, a ponto de Renato Lessa, em sua obra $A$ invenção republicana, caracterizála como os 'anos entrópicos', tomando emprestado da química o conceito de 'entropia', ou seja, desordem que se auto-alimenta. No entanto em 1903, embora na primeira década do século XX, estávamos na já segunda década republicana. Década que foi, também, bastante turbulenta. Basta lembrar, além da greve nesta obra estudada, da Revolta da Vacina em novembro de 1904, também no Rio de Janeiro, e da greve pela jornada de oito horas de trabalho em 1907, em São Paulo e no Rio de Janeiro, entre inúmeros outros movimentos sociais de maior ou menor dimensão.

$\mathrm{Na}$ verdade, todas as quatro décadas, para ficarmos nos marcos da chamada República Velha, foram turbulentas ou atravessadas por conflitos sociais explícitos e violentos. Na terceira década republicana, a Revolta da Chibata (1910) e, ao seu final, o ascenso do movimento operário e sindical, simbolizado, entre outras, pela greve geral paulista de julho de 1917 e pela tentativa insurrecional anarquista, articulada a uma greve também generalizada, em novembro de 1918 na capital federal (o "soviet do Rio", na expressão de Moniz Bandeira em $O$ ano vermelho: a Revolução Russa e seus reflexos no Brasil). Na quarta década republicana, última da República Velha, os protagonistas foram os militares, tenentes e capitães, rebeldes: 1922 no Rio de Janeiro, 1924 em São Paulo, a Coluna Prestes (1925-1927). Em suma, turbulências que vão do golpe que derruba Pedro II e a monarquia ao movimento que depõe Washington Luiz, turbulências de Deodoro a Vargas. Era bem relativa a 'paz oligárquica' da política dos governadores, do federalismo hegemônico, dos coronéis e 'currais eleitorais'.

Voltando ao livro que é objeto desta resenha, o capítulo 3, “O diário da greve", comenta e analisa notícias, artigos e editoriais publicados por diversos órgãos da imprensa carioca, do dia 12 de agosto, quando a greve é deflagrada, ao dia 5 de setembro de 1903, quando ela termina. O epicentro do movimento, no que diz respeito às reuniões de trabalhadores para discutir reivindicações e outras questões, ou mesmo para construir estratégias de articulação entre as várias categorias profissionais, é a região central da capital federal, onde estão localizadas as sedes dos sindicatos e associações operárias, entre as quais se desta- 
cam a Federação dos Operários em Fábricas de Tecidos e a Liga dos Artistas Alfaiates. O largo do Capim é o "coração do movimento grevista" (p.187). Teria sido interessante se a autora tivesse esclarecido o leitor sobre a localização exata do referido largo. Muitos logradouros centrais são citados: o largo de São Francisco, a rua do Ouvidor, a rua do Hospício (atual Buenos Aires), os bairros da Saúde e da Gamboa, entre inúmeros outros. É também referida uma "praça General Osório" (p.59), que certamente não é a praça que hoje tem esse nome, em Ipanema, à época um longínquo e pouco habitado areal.

A greve não se restringe, entretanto, ao centro do Rio de Janeiro. Na realidade, ela tem início no bairro das Laranjeiras, na Fábrica de Tecidos Alliança, então uma das maiores fábricas têxteis da cidade. As reivindicações são as clássicas: aumento salarial e redução da jornada de trabalho. Além disso, os operários exigem a recontratação de duas operárias arbitrariamente demitidas. Em relação à jornada de trabalho, é interessante constatar que bem no início do século XX o movimento operário e sindical no Brasil já incorporava essa reivindicação emblemática da luta dos trabalhadores, que remete à Inglaterra do século XIX (ver, por exemplo, os estudos de E.P. Thompson e E. Hobsbawm): oito horas de trabalho, oito horas de repouso, oito horas de lazer. A própria origem do $1^{\circ}$ de maio como dia internacional do trabalho está vinculada ao massacre de Chicago (1886), episódio de uma greve cuja principal reivindicação era a jornada de oito horas.

Aqui, mais um mérito para o livro da professora Francisca. A historiografia tem comentado a importância da greve de 1907, muitas vezes caracterizando-a como aquela que teria pela primeira vez explicitado a jornada de oito horas de trabalho como bandeira de luta. A pesquisa da autora do "Diário da greve de 1903" mostra como esta é uma reivindicação central do movimento, até mesmo unindo na luta diversas categorias profissionais: tecelões, alfaiates, chapeleiros, pintores, vidreiros, sapateiros, canteiros e outros operários das pedreiras, depois estivadores e catraieiros. A luta pela redução da jornada de trabalho, a simbólica jornada de oito horas como bandeira é, com efeito, uma luta que unifica, para além da diversidade das reivindicações salariais.

No decorrer dos dias, a greve se espalha por diversos bairros da cidade: São Cristóvão (fábrica de vidros Esberard, entre outras), Vila Isabel (Confiança Industrial), Andaraí (Cruzeiro), chegando à Zona Sul Botafogo (Corcovado), Jardim Botânico (Carioca) - e mesmo ao remoto bairro de Bangu. À medida que a greve se amplia, começa a alarmar não só o patronato mas também as autoridades governamentais. A deflagração da greve pelos tecelões da Fábrica Alliança leva os patrões a solicitarem a intervenção policial, comportamento que vai se tornando padrão. Cardoso de Castro, chefe de polícia do Distrito Federal, envia brigadas de cavalaria e infantaria para "manter a ordem e a tranqüilidade públicas", "garantir a propriedade" e também a "liberdade de trabalho" dos operários que não quisessem aderir ao movimento paredista. Laranjeiras assume ares de praça de guerra, o clima fica tenso, ocorrem escaramuças entre policiais e grevistas, que muitas vezes se refugiam nas ladeiras do bairro, Ladeira Mundo Novo, Ladeira do Ascurra. 
Ao mesmo tempo, patrões e agentes do Estado começam a construir/ reafirmar o discurso, nas palavras da autora, da "divisão maniqueísta da classe operária entre bons operários ... e os maus, os anarquistas estrangeiros infiltrados na classe trabalhadora brasileira" (p.179-180). De fato, já nos primeiros anos do século $\mathrm{XX}$ os discursos patronal e estatal começam a tentar desqualificar o anarquismo, elegendo o socialismo libertário como inimigo, caracterizando os anarquistas como "baderneiros, desordeiros, masorqueiros, agitadores profissionais, subversivos, estrangeiros ingratos, apátridas, homens sem honra, sem família, sem Deus", em suma, a "escória da humanidade". Em contraste, os trabalhadores brasileiros seriam "dóceis, honrados, laboriosos", vítimas da "infiltração anarquista". Nas palavras da autora: "Alguns jornais da cidade e a polícia insistem em insinuar que não são os trabalhadores brasileiros os responsáveis pelos distúrbios, mas os anarquistas estrangeiros que vieram agitar a cidade" (p.70).

Muitos operários são presos, vários espancados. Reagindo às violências e arbitrariedades policiais, trabalhadores distribuem por diversos pontos da cidade um panfleto, que termina com uma proposta bem radical: "Não recuaremos. Quando os encarregados de manter as leis as desrespeitam e rasgam, o povo também tem o direito de revoltar-se. Às vossas violências e arbitrariedades responderemos com a dinamite e o petróleo..." (p.69-70). Começa a se manifestar, segundo os patrões, em longa carta enviada pelo Centro Industrial de Fiação e Tecelagem de Algodão ao presidente da República, "o sopro da anarquia que inflama os espíritos e fomenta as perturbações do trabalho..." (Correio da Manhã, 22 ago. 1903, transcrito à p.110). No dia anterior, também o Jornal do Comércio, porta-voz do empresariado, publicara uma carta exigindo o fim da greve e advertindo os operários: "Mas precisamos não nos embalarmos em utopias..." (p.107).

Essa 'divisão maniqueísta' da classe operária - 'bons brasileiros' versus 'maus estrangeiros anarquistas' - vai, ao longo dos anos, se consolidando no discurso patronal e também no discurso governamental sobre a 'questão social'. Quinze anos depois, por ocasião da tentativa insurrecional anarquista no Rio de Janeiro, em novembro de 1918, tal visão reaparece num editorial intitulado "O joio e o trigo": o trigo, naturalmente, são os 'brasileiros laboriosos' e o joio, os 'anarquistas estrangeiros' (ver Carlos Addor, A insurreição anarquista no Rio de Janeiro). Patrões e membros do governo, em sua maioria, também acreditam que no Brasil os operários vivem bem, que não existem razões para a 'questão social', não há motivos para greves.

Periódicos e jornalistas de oposição e/ou descontentes com os rumos da República publicam editoriais e artigos criticando, muitas vezes ironizando, esse discurso e a atuação do governo: “Não há motivo nenhum para greve ... O operário, afinal, vive melhor que qualquer de nós. Muito. Passa um vidão ... Ainda o operário se queixa ... É porque ainda não lançou os olhos para as amarguras que sofre a infeliz e abandonada classe dos capitalistas" (O Paiz, 22 ago. 1903, transcrito às p.108109). Ainda nessa linha da ironia, o periódico Rio Nu chama a capital federal (a "Sebastianópolis") de "Grevópolis" e afirma: "a polícia, resolvendo agir energicamente, mandou prender a atriz Carmen Paredes" 
(p.194-195). O Correio da Manhã comenta, também com ironia, a participação na greve de menores que trabalhavam numa fábrica de biscoitos, afirmando que a diretoria, para impedir a "greve infantil", deveria "distribuir biscoitos pelos grevistas" (27 ago. 1903, transcrito à p.181).

Depois de cerca de três semanas de fábricas fechadas, o porto do Rio paralisado com a adesão de estivadores e catraieiros, inúmeras reuniões nas sedes de sindicatos e associações operárias (e também nas associações patronais), conflitos de rua, demissões de lideranças do movimento, patrões e autoridades governamentais se dispõem, por fim, a negociar. A greve e as negociações dela decorrentes "trouxeram alguns resultados positivos para a classe trabalhadora" (p.189). Algumas categorias profissionais conseguem aumentos salariais, outras conquistam a redução da jornada de trabalho. A greve vai se encerrando e a cidade vai, no início de setembro, retomando sua vida cotidiana. "Na segunda feira, 7 de setembro de 1903, o Rio de Janeiro pôde comemorar a Independência do Brasil com a volta ao trabalho de todas as categorias operárias" (p.213).

Acreditamos que a autora poderia ter comentado a expressão "malandros desconsolados", que dá título ao livro: ela aparece (à p.198) num artigo do historiador e jornalista Rocha Pombo - aliás, simpatizante do anarquismo, vindo a proferir no ano de 1904 palestras na Universidade Popular de Ensino Livre -, publicado pelo Correio da Manhã em 31 de agosto de 1903, no qual o escritor critica o governo e ironiza o discurso segundo o qual no Brasil, país tão opulento, não poderia existir miséria. Cremos também que o leitor sentirá falta de uma conclusão ou de algumas considerações finais. De qualquer forma, a professora Francisca de Azevedo produziu um instigante "Diário da primeira greve geral no Rio de Janeiro". 